Acta Poetica $35 \cdot 2$

JULIO-DICIEMBRE

$2014(97-117)$

\title{
El proceso místico en Del templo de su cuerpo, poemario de Rubén Bonifaz Nuño
}

\author{
Jocelyn Martínez Elizalde
}

Este trabajo propone una interpretación de la estructura estrófica y simbólica de Del templo de su cuerpo (1992), libro de poemas de Rubén Bonifaz Nuño (Veracruz, México, 1923), de acuerdo con su relación con la cábala. La cábala es "un método de contemplación religiosa, un sistema teosófico basado en las sefirot o emanaciones de la divinidad, que utiliza algunas técnicas para interpretar las letras del alfabeto hebreo con el fin de llegar a la elevación mística". Pero en Del templo de su cuerpo, el lector observará que la cábala es también un proceso que conduce al conocimiento y busca la "elevación mística", con la diferencia de que no es el alma lo que se sublima, sino el cuerpo. Del templo de su cuerpo es un complejo sistema de símbolos poéticos que presenta un ejemplo de la poesía erótico-mística. Este libro contiene algunos símbolos que representan el acto sagrado: el círculo perfecto, el abrazo de los amantes y el andrógino. Además, cada una de las sefirot tiene una conexión elaborada con otros símbolos: partes del cuerpo, colores, días de la semana, planetas, elementos naturales, signos zodiacales... todo funciona en un perfecto equilibrio, que se fundamenta en el cuerpo de la mujer. La poesía de Rubén Bonifaz Nuño es una búsqueda de la salvación del cuerpo a través del amor y de la palabra, un breve intento por permanecer.

PALABRAS ClAVE: Cábala, símbolos, poesía mística, andrógino, sefirot, mística erótica.

This work proposes an interpretation of the strophic structure of Del templo de su cuerpo (1992), book of poems by Rubén Bonifaz Nuño (Veracruz, México, 1923 ), according to its symbolic relation with the Kabbalah. Kabbalah is "a method of religious contemplation, a theosophical system based on the sefirot 
or emanations of divinity which uses certain techniques to interpret the letters of the Hebrew alphabet in order to reach the mystical elevation". However, in Del templo de su cuerpo, the reader will find that Kabbalah is also a process that leads to knowledge and seeks the "mystical elevation", with the difference that what is sublimated is not the soul, but the body. Del templo de su cuerpo is a complex system of poetic symbols that presents an example of mystical erotic poetry. This book contains symbols that represent the sacred act: the perfect circle, the embrace of the lovers, and the androgyne. Also, each of the sefirot has an elaborate connection with other symbols: parts of the body, colors, days of the week, planets, natural elements, Star Signs... everything works in a perfect balance, held by the female body. The poetry of Rubén Bonifaz Nuño is a quest for the salvation of the body through love and words, a brief attempt to remain.

KEYWORDS: Kabbalah, symbols, mystical poetry, androgyne, sefirot, mystical erotic.

Fecha de recepción: 21 de agosto de 2013

Fecha de aceptación: 27 de enero de 2014 
Jocelyn Martínez Elizalde

Universidad Nacional Autónoma de México

Facultad de Filosofia y Letras

\section{El proceso místico en Del templo de su cuerpo, poemario de Rubén Bonifaz Nuño}

De acuerdo con Angelina Muñiz Huberman, la cábala es "un método de contemplación religiosa, un sistema teosófico basado en las sefirot o emanaciones de la divinidad, que emplea ciertas técnicas para interpretar las letras del alfabeto hebreo con el propósito de alcanzar la elevación mística" (Las raíces y las ramas, 107). En el caso del poemario Del templo de su cuerpo (1992) de Rubén Bonifaz Nuño (Córdoba, Veracruz, 1923 - Ciudad de México, 2013), el lector encontrará que, efectivamente, se trata de todo un proceso que conduce al conocimiento y que pretende un encuentro divino, con la diferencia de que no es el alma la que se sublima, sino el cuerpo. En Del templo de su cuerpo, la experiencia carnal del amor llevará a los amantes a alcanzar el éxtasis místico: un orgasmo cósmico que equilibra todas las fuerzas; ${ }^{1}$ éste se deriva exclusivamente de la perfección y de la armonía del acto erótico y se representará en el poemario de diversas formas: el círculo, el abrazo, la rosacruz y el andrógino.

En cuanto al título del poemario, Del templo de su cuerpo, es necesario resaltar que difícilmente un poemario inicia con la preposición "de",

${ }^{1}$ Está relacionado con la "Hierogamia" o matrimonio sagrado, el cual representa la unión entre Dioses o parejas divinas (ver Giovanni Filoramo, Diccionario Akal de las Religiones, 263). 
más extraño es encontrarlo en forma de contracción "del", el título Del templo de su cuerpo posee, de inicio, cierta ambigüedad en el adjetivo posesivo, mismo que nos obliga a preguntarnos ¿del cuerpo de quién?, ¿se trata de un ente femenino o masculino?, éste será un juego constante en la poesía de Bonifaz Nuño, específicamente en sus poemas de tono místico, en los que con frecuencia la ambigüedad del género crea dos posibilidades de lectura: a veces se trata de una invocación al Amado; y en otras, a la amante. La frase "del templo de su cuerpo" proviene específicamente de un pasaje bíblico ampliamente conocido (Juan II, 19-23), cuando Jesús encuentra el templo plagado de comerciantes y, lleno de indignación, advierte a los judíos: "Destruid este templo, y en tres días lo levantaré", pero ellos, incrédulos, responden: "En cuarenta y seis años fue este templo edificado, ¿y tú en tres días lo levantarás?" A lo que Juan explica: "Mas él hablaba del templo de su cuerpo. Por tanto, cuando resucitó de los muertos, sus discípulos se acordaron que había dicho esto". Se evidencia, en términos generales, la ambigüedad de esta frase, incluso desde el referente bíblico: el templo es la construcción sagrada hecha para la adoración, la meditación y el encuentro con la divinidad, es el lugar donde se lleva a cabo el ritual, por lo tanto no debe ser mancillado; pero al mismo tiempo, el templo es también el cuerpo mismo, el cual debe pasar por un proceso de pruebas para ser digno del encuentro con la divinidad.

El título de este poemario tiene, además, dos referencias importantes. La primera proviene del judaísmo: la Shejiná; y la segunda de la tradición masónica: el Templo de Salomón. La Shejiná simboliza "la morada interior de Dios en el mundo: la presencia divina y recóndita, que hay que llegar a descubrir. En este sentido, equivale a la décima esfera, es decir, Maljut (o Malkuth), el reino de este mundo" (Muñiz Huberman, Las raices y las ramas, 71).

De acuerdo con Muñiz Huberman, en la tradición cabalística la Shejiná "encarna el principio femenino: la madre, la esposa, la hija. Otra referencia establecida por esta nueva interpretación de la Shejiná es la de atribuirle la morada del alma”. Ambas acepciones de la Shejiná, tanto la de "morada del alma" como la de la representación de lo femenino concuerdan perfectamente con Del templo de su cuerpo, al ser éste un poemario cuyo tema principal es el cuerpo femenino como habitación 
equilibrada y perfecta del alma. En este sentido, "la Shejiná, relacionada con el mundo femenino y con el alma, es una representación lunar y, como tal, está sujeta a cambios, fases y opuestos. Puede ser la parte iluminadora o la parte oscurecedora, la piedad o la severidad" (72). La característica de los opuestos se encuentra de forma evidente, como se verá más adelante, en la representación de la cábala, donde pueden apreciarse dos columnas: la del rigor y la de la compasión, que simbolizan los opuestos femenino-masculino, izquierda-derecha, agua-fuego; y en medio, la columna del equilibrio que condensa los opuestos y que se sostiene por Malkuth, el Reino de Dios.

La segunda referencia relacionada con el título del poemario pertenece a la tradición masónica, en específico al simbolismo atribuido al Templo de Salomón, cuyos pilares, Boaz y Jachin, forman parte de la representación de la cábala y equivalen a las columnas del rigor y de la compasión. Además, el Templo de Salomón, de acuerdo con Jean Chevalier, "es un modelo de simbólica geométrica, ya que sus medidas son simétricas y en él abundan las formas cuadrangulares, por lo que posee un simbolismo cósmico. El templo representa el cosmos y cada objeto contenido en el templo se encuentra ordenado" (Diccionario de los simbolos, 986).

Del templo de su cuerpo está constituido por 37 poemas que, en su estructura y en su temática, guarda relación con la cábala. Lo conforman 10 poemas titulados con los nombres de las sefirot: "I. Kether", "II. Binah", “III. Chokmah”, “IV. Chesed”, “v. Gueburah”, “vI. Tiphareth”, "VII. Netzach", “VIII. Hod", “Ix. Yesod" y "x. Malkuth". Entre cada uno de estos poemas se encuentran distribuidos - de tres en tres- los otros 27 poemas titulados con las letras del alfabeto. Del templo de su cuerpo se basa en una equivalencia con las 27 letras del alfabeto español en comparación con las 22 letras del alfabeto hebreo, lo cual habla de la importancia que el autor le brinda a la lengua española, pues prefiere una versión parcialmente castellanizada de la cábala; sin embargo, en los nombres de las sefirot utiliza una versión en inglés. ${ }^{2}$ Aunque es

${ }^{2}$ De acuerdo con Esther Cohen, los nombres castellanizados de las sefirot son: Keter, Jojmah, Binah, Jesed, Gevurah o Din, Tiferet, Netzah, Jod, Yesod, Maljut (Zohar. Libro del esplendor, 17). 
común hallar la correspondencia entre las letras hebreas y el alfabeto latino, en el caso específico de este poemario el poeta agrega - además- las letras "F", "I", "Ñ", "O", "U", "V", "X" e "Y".

En las distintas interpretaciones de la cábala judía se ha encontrado que existe una compleja equivalencia entre sus elementos y las partes del cuerpo, los arcanos del tarot, los signos del zodiaco, los meses del año y los días de la semana. La siguiente imagen contiene, por una parte, los elementos con los que normalmente se le relaciona a la cábala $\mathrm{y}$, por otra, en la esquina superior derecha, la representación cabalística de la tradición masónica, cuyos símbolos se encuentran en cada uno de los poemas de las sefirot de Del templo de su cuerpo. Las sefirot están repartidas en tres columnas: la columna de la severidad o el rigor representa a su vez la parte femenina, el agua, el color rojo y la inteligencia; la columna de la izquierda es la compasión o misericordia, representa la parte masculina, el fuego y el color blanco. La columna del centro es la unión y el equilibrio de las laterales, en ella se conjugan las fuerzas opuestas. $^{3}$

3 Boaz y Jachin son los dos pilares de bronce fundidos por Hiram Abif de Tiro, llamado "el Hijo de la Viuda" para el Templo (masónico) de Salomón (ver Juan Carlos Daza, Diccionario Akal de Francmasonería, 86-87). La interpretación de los elementos simbólicos relacionados con la cábala masónica, principalmente los que se señalan en este esquema y los colores, que se nombran en los poemas, se hace a partir de Dione Fortune, La cábala mística. 


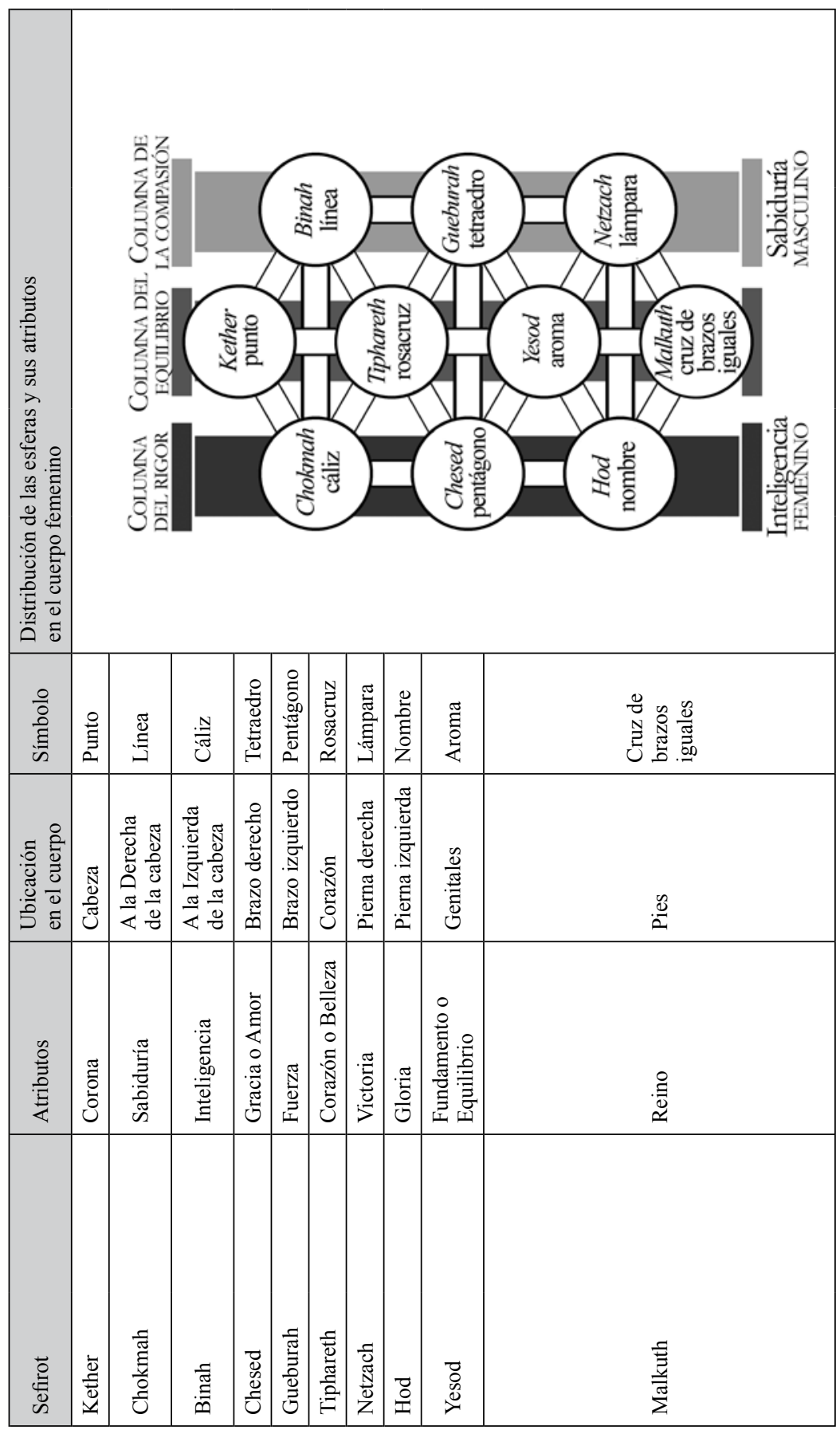




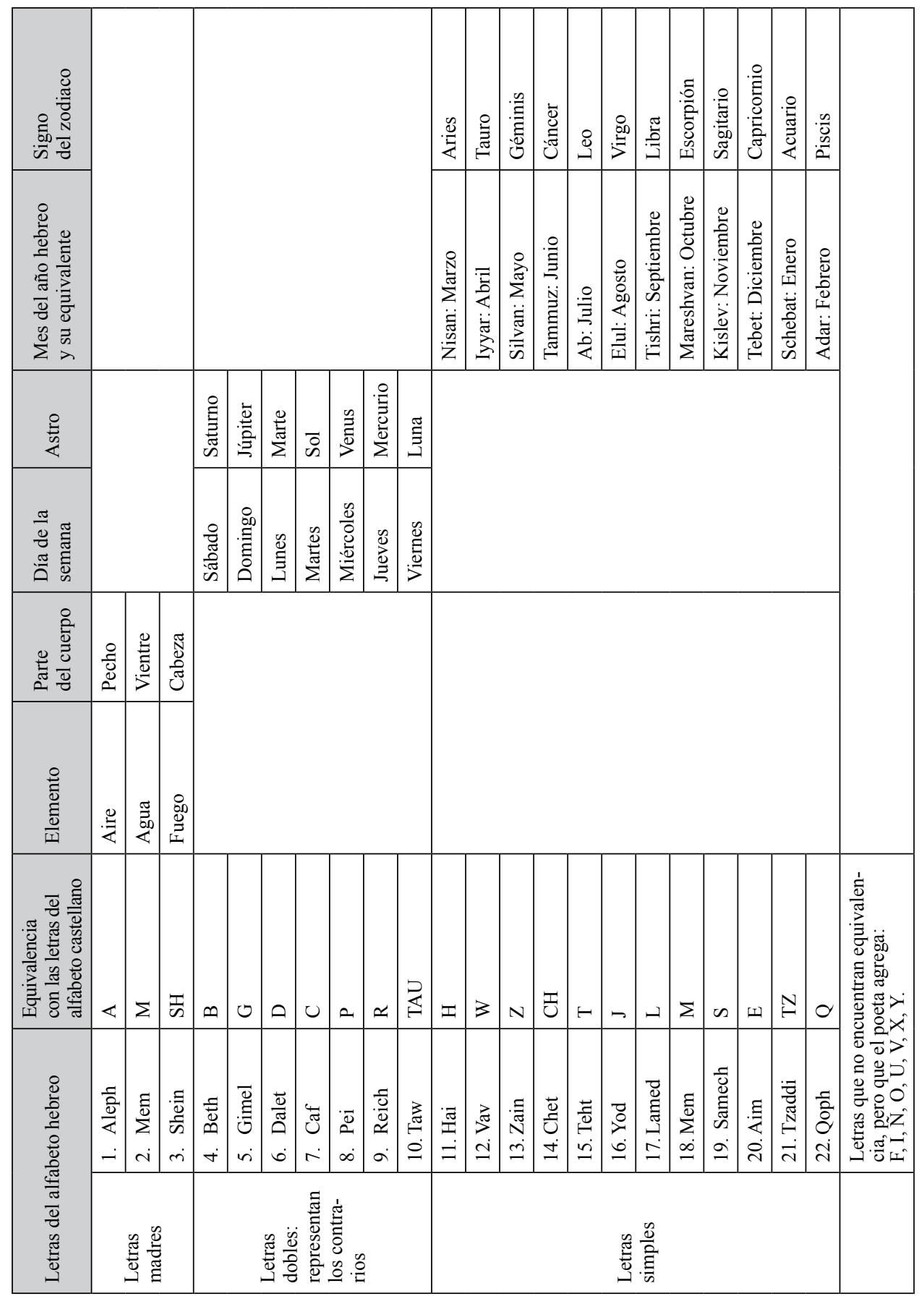


Este esquema es una propuesta de lectura para Del templo de su cuerpo, el cual nos permite afirmar que hay coincidencias y divergencias en la representación que Rubén Bonifaz Nuño hace de la cábala. En primer lugar, como se mencionó anteriormente, el poemario utiliza el alfabeto de la lengua española y no el del hebreo. En segundo lugar, el poeta privilegia la relación entre las esferas del árbol sefirótico y sus atributos, y disminuye el simbolismo relacionado con las letras.

Respecto a las correspondencias de las letras (los elementos, las partes del cuerpo, los días de la semana, los astros, los meses del año y los signos zodiacales) no se encuentran referencias claras en el poemario de forma específica; por poner un ejemplo, en el poema "C" no hay ninguna referencia al sol ni al día martes y así sucederá con el resto de los poemas titulados con letras. Sin embargo, la idea general de equilibrio y orden cósmico, que representan las letras del alfabeto y sus correspondencias en la cábala, se hallará siempre presente en el poemario. También se encontrarán correspondencias evidentes en el poema " $\mathrm{M}$ ", en el que se hace alusión al agua y al vientre (en este caso materno), elemento de la naturaleza y parte del cuerpo que tienen relación con la "mem" hebrea.

Respecto a la simbología con cada una de las sefirot se encuentran correspondencias evidentes en los atributos, las partes del cuerpo y el símbolo masónico respectivo. Además, cada poema está constituido por cuatro estrofas, tres de siete versos y la cuarta de seis, en las que se encontrará cierta constancia: en la primera estrofa siempre se hace referencia a la parte del cuerpo que le corresponde a la sefirá con la que se titula el poema, en la segunda y tercera estrofa hay una constante mención de colores y la última estrofa hace referencia al símbolo masónico acorde, los atributos de cada esfera también se encuentran mencionados en cada poema pero no de una forma rígida, ya que pueden aparecer en cualquiera de las cuatro estrofas. ${ }^{4}$ Como ejemplo de esta constancia se

${ }^{4}$ En la obra poética de Rubén Bonifaz Nuño se le da gran importancia a la estructura de los poemas que conforman cada uno de sus libros. Algunos están elaborados con base en una métrica tradicional. Por ejemplo, Madrigal del adolorido (ca. 1950) es una glosa del "Madrigal" de Gutierre de Cetina; el poemario está compuesto por 12 poemas donde alternan sonetos y madrigales; el último verso de cada poema es un verso inicial del "Madrigal" de Cetina. Por su parte, Fuego de pobres (1961) está compuesto por 38 
muestra un análisis comparativo de dos poemas: "IV Chesed" y "v Gueburah", las cursivas son mías:

\begin{tabular}{|l|l|}
\hline IV Chesed & $\begin{array}{l}\text { Atributo: Gracia o amor } \\
\text { Parte del cuerpo: brazo derecho } \\
\text { Símbolo masónico: Tetraedro } \\
\text { Columna: derecha, de lo masculino y de } \\
\text { la misericordia. }\end{array}$ \\
\hline $\begin{array}{l}\text { Él la misericordia; } \\
\text { amante, el brazo izquierdo. } \\
\begin{array}{l}\text { Coronado y solemne, } \\
\text { rey y pastor perfecto. }\end{array}\end{array}$ \\
\hline $\begin{array}{l}\text { La majestad en él } \\
\text { se consuma; el gobierno } \\
\text { justo; tras el combate, } \\
\text { el descanso sereno. }\end{array}$ & \\
\hline $\begin{array}{l}\text { Azul profundo, y de astros } \\
\text { amarillos, su cielo; } \\
\text { los sagrados poderes } \\
\text { ejerce, justiciero. }\end{array}$ & \\
\hline $\begin{array}{l}\text { Son suyos la armonía } \\
\text { cabal del tetraedro, } \\
\text { la cruz de iguales brazos, } \\
\text { el báculo y el cetro. } \\
\text { Trasponiendo el abismo } \\
\text { establece su reino. }\end{array}$ & \\
\hline
\end{tabular}

Desde un inicio es posible notar que ambos poemas reflejan las representaciones de la cábala ya mencionadas. En el primer verso de cada

poemas constituidos por versos de 7 y 11 sílabas, con imitación de ritmo y figuras de la poesía náhuatl, integración de refranes, frases populares y música popular mexicana. La estructura de los poemarios de Bonifaz Nuño también puede estar basada en relaciones simbólicas; por ejemplo, Siete de espadas está integrado por 143 poemas compuestos por estrofas de siete versos de once, diez y nueve sílabas; de acuerdo con el autor esta estructura se corresponde con los días de la semana, el arcoíris, la escala musical, los pecados y las virtudes, el corazón de la Dolorosa, la carta de la baraja con sus significaciones. Un ejemplo más es El ala del tigre, poemario constituido por 85 poemas de tres estrofas de seis versos cada una, en los que alternan decasílabos y eneasílabos; en este poemario la estructura es regular: la primera y la tercera estrofa se contraponen y la de en medio equilibra a las otras dos. 


\begin{tabular}{|c|c|}
\hline $\begin{array}{l}\text { Atributo: Fuerza } \\
\text { Parte del cuerpo: brazo izquierdo } \\
\text { Símbolo masónico: Pentágono } \\
\text { Columna: izquierda, de lo femenino y } \\
\text { del rigor. }\end{array}$ & v Gueburah \\
\hline & $\begin{array}{l}\text { Bélico rey severo; } \\
\text { su signo, y el diestro brazo; } \\
\text { robusto y combatiente } \\
\text { rige, en armas, su carro. }\end{array}$ \\
\hline & $\begin{array}{l}\text { El temor lo acompaña, } \\
\text { destructor del engaño; } \\
\text { con el miedo, el amor } \\
\text { completa, acrecentándolo. }\end{array}$ \\
\hline & $\begin{array}{l}\text { Valiente sin defecto, } \\
\text { corta y mata lo insano; } \\
\text { sus resplandores rojos } \\
\text { son de negro horadados. }\end{array}$ \\
\hline & $\begin{array}{l}\text { Y suyos son la rosa } \\
\text { regular del pentágono } \\
\text { y la espada y el asta, } \\
\text { la cadena y el falo. } \\
\text { Y, no indulgente, lucha } \\
\text { y hiere, fuerte y sano. }\end{array}$ \\
\hline
\end{tabular}

poema aparecen las palabras "misericordia" y "severo", características opuestas que representan los dos pilares de la cábala de la tradición masónica: la columna del rigor y la columna de la compasión. En el segundo verso de cada poema se encuentran mencionadas las partes del cuerpo en donde se ubica cada sefirá; como se puede ver, en el poema aparecen de forma contraria "brazo izquierdo" y "diestro brazo". Tanto en los siguientes dos versos como en la segunda estrofa encontraremos palabras con significado semejante y que corresponden nuevamente a los pilares. Por un lado, en "Chesed", esfera ubicada en el lado de la misericordia, tenemos "majestad", "perfección", "justo", "justiciero", "armonía cabal"; todas éstas son referencias al equilibrio y a la entere- 
za, cualidades que también están relacionadas con los atributos que le corresponden a dicha esfera de la cábala: la Gracia y el Amor. Por otra parte, en el poema "Gueburah", esfera localizada en el lado del rigor, se lee "bélico", "severo", "combatiente", "valiente", "no indulgente"; estas cualidades, a su vez, se relacionan con el atributo que le corresponde: la Fuerza.

Asimismo, es notable que en ambos poemas se hable de reyes y que - aunque con características contrarias - en los dos se logre el equilibrio. Más adelante se verán otros ejemplos en los que también se muestran elementos opuestos en los poemas que corresponden a las esferas de las columnas laterales. Incluso, aunque en "Chesed" y en "Gueburah" no aparece la correspondencia con los géneros femenino y masculino, ya que en los dos se presenta el rey como figura masculina, sí aparecerá este encuentro entre géneros en otros poemas de lado izquierdo y derecho, particularmente en "Chokmah" y "Binah", cuyo análisis de algunos de sus versos se verá más adelante.

En "Chesed" y en "Gueburah", encontramos que en la tercera estrofa de ambos se encuentran mencionados dos colores: en el primero "azul" y "amarillos" y en el segundo "rojos" y "negro". Como mencioné anteriormente, en todos los poemas titulados con los nombres de las esferas aparecerán entre la segunda y la tercera estrofa dos o más colores o palabras relacionadas con éstos: En "I Kether": "Blanca lumbre, / de estrellas de oro recorrida". En "II Chokmah": "de gualda, ${ }^{5}$ azul y púrpura / blancura perdurable”. En "III Binah": "La luz agrisa; oscura, / la rocía de rosas". En "vi Tiphareth": "divino sol propicio, / y su luz se difunde / en ámbar de oro místico". En "VII Netzach": "El verde oliva, el oro, / iluminan su esfera". En "VIII Hod": "El negro amarillento / con blanca luz adorna". En "IX Yesod: "Con azul y amarillo / ilumina su mundo" En "x Malkuth": "entre rejas doradas / confina las tinieblas".

Como puede observarse, el color que se repite en todas las esferas es el amarillo o el dorado, de igual forma pueden identificarse palabras que responden a la isotopía de estos colores como "lumbre", "oro", "sol", "luz" y "ámbar". Es de esperarse que este color prevalezca, puesto que el amarillo simboliza, para diversas culturas, el poder y la sabiduría

${ }^{5}$ Gualdo, da: adj. Del color amarillo de la flor de la gualda (DRAE). 
de los reyes, pero también la pureza y la eternidad de los elementos, así como el renacer del día, del sol y de las estaciones; explica Jean Chevalier: "el amarillo es el más caliente, expansivo y ardiente de los colores; difícil de entender, desborda siempre los marcos donde se le quiere ceñir" (Diccionario de los símbolos, 87). En todos los versos en que el amarillo aparece, lo hace en forma de luz o de fuego que alumbra y quema, con lo que se intuye la presencia de un ritual y de una transformación.

Por último, en la cuarta estrofa de cada poema aparecerán los símbolos de la masonería, que se corresponden con la sefirá que llevan por título: Chesed, el tetraedro, y Gueburah, el pentágono. Además, se incluyen otros símbolos pertenecientes a esta misma tradición: la cruz de iguales brazos y la rosa, todos ellos símbolos del equilibrio, la perfección y la unión de contrarios.

Asimismo en cada una de las últimas estrofas de los otros ocho poemas titulados con los nombres de las esferas se encontrará el símbolo masónico correspondiente: en "I Kether" (el punto): "Principio elemental / y fuente; geometría". En "II Chokmah" (la línea): "Suyos, después, hoy, antes, / la torre engendradora / el cetro fecundante". En "III Binah" (el cáliz): "Suyas, la vulva; eterna, / la hondura de la copa". En "VI Tiphareth" (la rosacruz): "Suyas, la cruz, la rosa / que en la cruz tiene asilo / la pirámide trunca, / el cubo, son su símbolo". En "VII Netzach" (la lámpara): "El blanco ceñidor, / la lámpara despierta". En "VIII Hod" (el nombre): "Los nombres son lo suyo / el mandil, las estrofas". En "IX Yesod" (el perfume): "Suyas son las sandalias / el aroma es lo suyo / [...] conservar las esencias / enteras, su atributo" En "x Malkuth" (la cruz de brazos iguales): "Suyos, la cruz, el círculo / que la magia abre y cierra".

Como puede verse, no todos los símbolos aparecen tal cual; por ejemplo en el caso de Kether no aparece la palabra "punto", pero se trata del principio elemental de la geometría, tal como lo poetiza el autor. En el caso de Chokmah y Binah, tampoco aparece de forma literal; es necesario llevar a cabo una serie de analogías en las que la torre y el cetro podrían considerarse imágenes con forma lineal, que en este caso aluden también a símbolos fálicos, ya que en el poema la torre es "engendradora" y el cetro es "fecundante". Estos símbolos se corres- 
ponden, además, con la sefirá que se ubica paralela a Chokmah, pero en la columna contraria, es decir, Binah, cuyo atributo es el cáliz, mencionado en el poema como la copa. En el poema también se agrega "la vulva eterna" relacionado, a su vez con lo femenino. En "Tiphareth" no aparece como tal la rosacruz, pero sí "la rosa que en la cruz tiene asilo".

En la tradición hebrea, las esferas se encuentran distribuidas en el cuerpo de Adam Kadmon o ser primordial; en el poemario de Rubén Bonifaz Nuño las esferas también se encuentran en el cuerpo, pero en este caso en un cuerpo femenino. Es notable que aunque se conservan las características de las esferas de los costados, en el poemario éstas cambian de lugar, como si fueran percibidas a través de un espejo. Si regresamos al esquema veremos que Chokmah, Chesed y Netzach corresponden a las partes derechas del cuerpo: cabeza, brazo y pierna; por su parte, Binah, Gueburah y Hod se localizan en la parte izquierda. Sin embargo, reitero que en el poemario, Del templo de su cuerpo, se encuentran de forma opuesta. Por ejemplo, en el poema "II. Chokmah", se lee en la primera estrofa: "Amor, misericordia; / del rostro izquierda parte. / Supremo de la fuerza, / libre y sin muerte: padre". Y posteriormente en "III. Binah": "Magna matriz, la madre / de la muerte dadora; / diestra parte del rostro, / la todopoderosa".

Nótese que, en el poema bonifaciano, Chokmah se ubica en la parte izquierda, tiene como característica la misericordia y se relaciona con lo masculino: el padre; por su parte, Binah se encuentra en la parte derecha y se relaciona con lo femenino: la madre. Es decir, cambian los lados izquierdo y derecho, pero no los atributos de las columnas que tienen las siguientes correspondencias: lado izquierdo, de lo femenino, del rigor, de la inteligencia; lado derecho, de lo masculino, de la misericordia, de la sabiduría.

Este mismo intercambio de lados, pero no de atributos, sucederá con otros dos poemas que se refieren a las esferas que se encuentran en los costados del cuerpo: Gueburah y Chesed. Por lo tanto se lee en "IV Chesed": "Él, la misericordia; / amante, el brazo izquierdo" frente a "v Gueburah": "Bélico rey severo; / su signo, el diestro brazo", cuando al primero le corresponde el brazo derecho y al segundo, el izquierdo.

Asimismo, es necesario destacar que la protagonista de este poemario es percibida por medio de todos los sentidos, salvo la vista, 
ya que el sujeto lírico se asume como ciego, el cuerpo de la mujer aparecerá siempre sin cabeza, tal como lo comenta el poeta en una entrevista: "Si lees todos los poemas, verás que no se habla de ojos, ni de bocas ni de narices ni de cabellos; esa parte del cuerpo se omite y se habla, simplemente del cuello para abajo" (Estrada, De otro modo el hombre, 108).

La explicación que brinda el poeta es la siguiente:

Son poemas escritos a una atleta de triatlón. Para mí, fue sorpresa el concepto que esa atleta tiene de su propio cuerpo. Cuando escribí poemas para una bailarina, sabía que para ella el cuerpo era un instrumento de arte: el instrumento de expresión es el cuerpo, para expresar cosas interiores $[\ldots]^{6}$

En cambio, para la atleta, según me percaté con esta persona, el cuerpo es una finalidad. La atleta considera su cuerpo como su propia esencia; por eso en alguna ocasión digo: "Tu arma es tu cuerpo". 7

Por lo tanto, el cuerpo femenino sobre el que se distribuyen los elementos de la cábala debe ser considerado sin cabeza y con las esferas de los costados invertidas. Esta visión de espejo, por supuesto, no afectará a las esferas del centro, en los poemas correspondientes a la columna de en medio (Kether, Tiphareth, Yesod y Malkuth), pues habrá siempre referencia al centro y al equilibrio. En "Kether": "Vértice sobre el vértice, / encima de la cima"; en "Tiphareth": "Belleza consumada, / centro del equilibrio"; en "Yesod": "Espíritu y materia / reconcilia en lo uno" y en "Malkuth": "La materia / enérgica de fuego / de agua, de aire, de tierra".

En cuanto a la estructura estrófica de los poemas de Del templo de su cuerpo, titulados con letras no existe una constancia, cada poema está compuesto de tres a siete estrofas de versos de 7, 9, 10 y 11 sílabas - los metros más utilizados en la poesía bonifaciana - y como único elemento persistente aparece el uso del encabalgamiento y del hipérba-

${ }^{6}$ Respecto a la bailarina se refiere a Los demonios y los días, poemario dedicado a Magda Montoya (Juchitán, Oaxaca), quien en 1950 fundó el Ballet de la UNAM.

${ }^{7}$ Hay aquí una errata, podría deberse a un error de transcripción de la entrevista o el autor recuerda su verso de forma incorrecta, ya que en el poema "N" de Del templo de su cuerpo se lee: "Tu alma es tu cuerpo" y no "tu arma". 
ton, de los cuales también se ha dicho que forman parte del estilo peculiar de Bonifaz Nuño. No obstante, la estructura de los poemas que llevan por título los nombres de las diez esferas es invariable, ya que todos están conformados por cuatro estrofas de versos heptasílabos; las primeras tres estrofas se componen de 4 versos y la última de 6 . La combinación 4 y 6 puede ser interpretada como la representación del cubo; recordemos que en este poemario las figuras geométricas son de gran importancia, ya que simbolizan la perfección y equilibrio cósmico, tal como se comenta de la estructura del Templo de Salomón.

Además, los números 4 y 6 representan el llamado sello de Salomón:



fuego

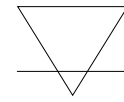

tierra

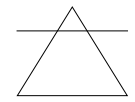

aire

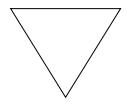

agua

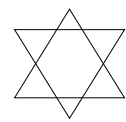

plata-Luna

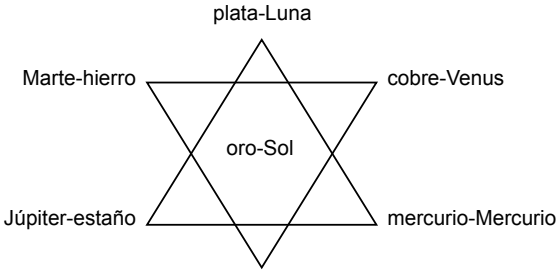

plomo-Saturno

El sello de Salomón forma una estrella de seis puntas, compuesta de dos triángulos equiláteros entrecruzados. Contiene los cuatro elementos (fuego, aire, tierra y agua) y representa la síntesis de los opuestos y la expresión de la unidad cósmica. Contiene además los siete metales y los siete planetas (Chevalier, Diccionario de los símbolos, 923).

Respecto a la importancia del cuerpo y a las dos estructuras de los poemas de este libro, Vicente Quirarte comenta:

en Del templo de su cuerpo el poeta no canta abstractamente el cuerpo femenino sino, de una manera concreta, el cuerpo de una mujer en plenitud de sus capacidades físicas y atléticas. Es un cuerpo pulido "por los esmeriles del maratón y la alberca", dolorido e iluminado por el ejercicio. De tal manera dos son las historias desarrolladas en el libro: una donde el aman- 
te reconstruye los fragmentos del instante total y único de la posesión; otra donde el cuerpo actúa como símbolo de la victoria presente (184).

Estas “dos historias", como las llama Quirarte, son dos estructuras a las que responden los poemas; la primera corresponde a las diez esferas de la cábala con una forma perfectamente definida de cuatro estrofas compuestas por 18 versos heptasílabos divididos en 4-4-4-6 - cuyas implicaciones simbólicas ya se han comentado-y en el que cada estrofa tendrá los atributos de la esfera que lleva por título, cada uno de estos poemas representa la perfección del cuerpo humano. La segunda estructura pertenece a los 27 poemas titulados con las letras del alfabeto, cuyo rasgo común es el encabalgamiento, probablemente la reiteración de este recurso métrico se debe a que éstos son poemas dinámicos, es decir con mayor capacidad narrativa. En los titulados con las esferas se encuentra el cuerpo inmóvil y perfecto, pero en los titulados con las letras se encuentra un cuerpo en movimiento.

En todo el poemario se hacen constantes alusiones a conceptos relacionados con la construcción y con la estructura de una casa como representación del cuerpo, pero sobre todo con la perfección de sus formas y con el valor de lo que allí se resguarda. En el poema "J" se dice:

Sin verte ni oírte, voy formándole

el molde de un instante tuyo;

el estuche justo, tu morada.

Espacio puro, impenetrable, donde guardarlo aprisionado.

Siguiendo los innumerables peldaños infinitesimales de tu olor, bajando y ascendiendo, las superficies reconozco, maravilladas, de tu cuerpo.

Y con él completo la armadura del perfecto espacio: tu recinto inequívoco, el sitio de ti misma. 
Este poema es un ejemplo de la manera en que Bonifaz Nuño describe el cuerpo femenino comparándolo con un ámbito espacial ("molde", "estuche", "morada", "espacio", "armadura", "recinto", "sitio") cuyas características son lo "justo", lo "puro", lo "impenetrable", lo "perfecto" y lo "inequívoco".

Otro de los poemas en los que aparece el símbolo de la morada es el "F"; la constante, en ambos, es poetizar el cuerpo femenino como un templo en el que habita el alma de la amada y al que al amante le es concedido entrar; además se insiste en que la estructura y el contenido, es decir, el cuerpo y el alma son uno solo; tal como se lee en el poema "N": "Y comprendes, comprendiendo el mundo, / y carne y alma son un solo / prodigio de ser: tu alma es tu cuerpo".

Desde esta perspectiva, en el poemario de Bonifaz Nuño el acto sexual logra la coexistencia total de los contrarios, dando lugar al andrógino:

La androginia aparece por tanto también como un signo de totalidad; restaura no solamente el estado del hombre original considerado como perfecto, sino el caos primitivo anterior a las separaciones creadoras; un caos que esta vez se ha vuelto ordenado sin haber perdido nada de su riqueza, ni haber roto nada de su unidad [...] La unión de lo masculino y lo femenino, de lo alto y lo bajo, de lo celestial y lo terrenal comporta también la unión de lo exterior y lo interior, lo de fuera y lo de dentro (Chevalier, Diccionario de los símbolos, 95-97).

La imagen de la unión mística en tanto la reconstrucción de un todo coincide también con el mito del andrógino de Platón, como escribe Moshe Idel:

Algunas fuentes posibles de la visión del hombre como un semicírculo y de su alma como parte del alma universal podrían ser: 1) la descripción platónica de la división del andrógino primordial esférico en dos mitades, macho y hembra; y 2) las versiones medievales de este mito, tanto árabe como judía, que transfirieron la división del cuerpo al alma (107).

Los poemas titulados con letras en los que aparece claramente la imagen del andrógino son dos: el poema "A", en el que el andrógino está simbolizado por el abrazo de los amantes y es más parecido al an- 
drógino esférico de Platón. En este poema de Del templo de su cuerpo se describe a los amantes precisamente como un ser doble y esférico: "Fue en el principio, nuestro abrazo, / el centro mellizo de esa esfera". Por otra parte, en el poema "N" el cuerpo de la mujer es poseído por el hermafrodita y posteriormente pareciera encarnar en ella misma el cuerpo de los dos sexos, y en ello radican su placer y su plenitud. En este poema también se hace alusión a la complementación de cuerpo y alma, haciendo mayor énfasis en lo carnal que en lo espiritual.

Papalote de carne y glándulas, vuelas sin soltarte de la tierra; y en tu carne se convierte el alma de todo; alma encarnada tuya, la lluvia, el viento hermafrodita que entra por tu piel en tus entrañas; el doble sexo a quien te entregas $\mathrm{y}$ te resiste y te sustenta.

Eres tu placer, y eres la mística unión sexual donde te integras, como las piedras y los árboles, al corazón de la existencia.

Orgasmo atlético; gemidos pulsan entre gritos jubilosos.

Otro texto que ahonda en la importancia del cuerpo como tal es "El cuerpo del engendramiento en la Biblia hebraica, en la tradición rabínica y en la Cábala" de Charles Mopsik, quien cita a un cabalista del siglo XVII, Rabbi Isaías Horowitz:

En un determinado grado, el cuerpo y el alma son iguales, es decir, ambos son espirituales, como lo era el primer hombre antes del pecado y como lo será en el porvenir [...] tal es la finalidad, que el cuerpo y el alma sean eternos (66-67). 
Asimismo, en el poema "IX. Yesod" de Rubén Bonifaz Nuño se lee: "Espíritu y materia / reconcilia en lo uno". En Del templo de su cuerpo abundan diversas imágenes simbólicas que constituyen la estructura cosmológica del poemario y que dan muestra del universo de referencias en la obra de Rubén Bonifaz Nuño. Al igual que en la cábala, en el poemario se nombran los atributos de cada una de las esferas; asimismo se agregan colores, aromas, figuras geométricas y números, así como símbolos de la tradición masónica y del hermetismo; todas estas referencias, en conjunto, hacen de este poemario un complejo sistema de símbolos poéticos que requieren ser interpretados para alcanzar la máxima comprensión del poemario que, entre otras cosas, se constituye como un libro de poesía amorosa, un homenaje a la perfección del cuerpo femenino y al erotismo.

No es ésta la primera vez que Rubén Bonifaz Nuño poetiza el cuerpo femenino como un espacio de adoración, en todos los sentidos de esta palabra, es decir, como elemento privilegiado, como espacio digno de admirar y gozar y como recinto supremo de la creación. No obstante, con frecuencia, esta adoración del cuerpo femenino es más en un tono coloquial. El cuerpo de la mujer se estructura como algo terrenal y, por lo tanto, perecedero; por lo general se trata de un cuerpo real, que se degrada, muy a pesar de los deseos del sujeto lírico, quien pretende perpetuar ese espacio de júbilo. En cambio, como se ha establecido desde un inicio, Del templo de su cuerpo utiliza un método de contemplación que pretende alcanzar la iniciación mística, pero ésta se logrará sólo a través de la carne; esta afirmación, aunque un poco escandalosa, no es contradictoria, ya que dentro de la tradición cabalística el cuerpo es en sí una composición privilegiada, estructurada anatómica y fisiológicamente perfecta. El poeta hace una elaborada fusión entre la descripción del cuerpo femenino, la estructura de la cábala y la disposición del poemario; asimismo, se lleva a cabo una serie de correspondencias en cuanto a los símbolos y un ritual de iniciación inherente que permite pensar a Del templo de su cuerpo como una vía hacia la divinidad corporal y al encuentro erótico. 


\section{REFERENCIAS}

Biblia Reina-Valera, American Bible Society, 1991.

Bonifaz Nuño, Rubén, Del templo de su cuerpo en Versos (1978-1944), México, Fondo de Cultura Económica, 1996.

Chevalier, Jean y Alain Gheerbrant, Diccionario de los símbolos, Barcelona, Herder, 1986.

Conen, Esther, La palabra inconclusa. Ensayos sobre Cábala, México, Universidad Nacional Autónoma de México, 2005.

DAzA, Juan Carlos, Diccionario Akal de Francmasonería, Madrid, Ediciones Akal, 1997.

Eliade, Mircea, Iniciaciones místicas, Madrid, Taurus, 1958.

Eliade, Mircea, Mitos sueños y misterios, Madrid, Grupo Libro 88, 1991 ("Libros perdidos").

Estrada, Josefina, De otro modo el hombre. Retrato hablado de Rubén Bonifaz Nuño, México, El Colegio Nacional, 2008.

FERNÁNDEZ-CHeCA, José Felipe Alonso, Diccionario de alquimia, cábala y simbología, Madrid, Máster, 1993.

Filoramo, Giovanni, Diccionario Akal de las Religiones, Madrid, Ediciones Akal, 2001.

Fortune, Dione, La cábala mística, trad. Vicente Morel, Buenos Aires, Kier, 2006 (Primera edición inglesa The Mysthical Qabalah, 1935).

IDEL, Moshe, Cábala. Nuevas perspectivas, Madrid, Siruela, 2005.

LiBIS, Jean, El mito del andrógino, Madrid, Siruela, 2001.

Mopsik, Charles, "El cuerpo del engendramiento en la Biblia hebraica, en la tradición rabínica y en la Cábala", en Fragmentos para una historia del cuerpo humano, Ramona Nadaff, Nadia Tazi y Michel Feher (coords.), Madrid, Taurus, 1992.

MuñIz Huberman, Angelina, Las raíces y las ramas. Fuentes y derivaciones de la Cábala hispanohebrea, México, Fondo de Cultura Económica, 2002.

Quirarte, Vicente, Rubén Bonifaz: El dolorido sentir. Antología de la poesía amorosa, México: Consejo Nacional para la Cultura y las Artes / Centro Cultural Tijuana / Universidad Nacional Autónoma de México, 1998.

Zohar, Libro del esplendor, traducción, selección, prólogo y notas de Esther Cohen, México, Consejo Nacional para la Cultura y las Artes, 2010. 